\title{
Ongoing Care and Follow-up Behavior of Working Age Japanese with Hepatitis C Virus
}

\author{
Koji Wada ${ }^{1, *}$, Derek R. Smith ${ }^{2}$ and Hisashi Eguchi ${ }^{3}$ \\ ${ }^{1}$ Bureau of International Medical Cooperation, National Center for Global Health and Medicine, Japan; ${ }^{2}$ School of \\ Health Sciences, Faculty of Health, University of Newcastle, Ourimbah, Australia; ${ }^{3}$ Department of Public Health, \\ Kitasato University School of Medicine, Sagamihara, Japan
}

\begin{abstract}
Background: Persons infected with HCV (Hepatitis C Virus) may not actively seek medical attention as they are often asymptomatic for long periods of time. Objective: The aim of this study was to investigate ongoing care and follow-up behaviors of working age Japanese who are currently infected with HCV. Methodology: We recruited a total of 156 persons aged 20-69 years ( 78 male and 78 female) who had been infected with HCV and were registered with an internet survey company. These individuals were asked to answer an anonymous questionnaire which focused on how they had found out about being infected with HCV, if they had received any specific treatment, their frequency of visits to medical facilities, and if they had received prior medication. Results: Of the 156 participants $35.9 \%$ reported havd no prior treatment at all, while $30.1 \%$ had no regular visits to medical facilities regarding their condition. The main reason for not visiting medical facilities was the lack of doctor's recommendation in $19.0 \%$ of men and in $31.4 \%$ of women respondents with HCV infection. Those who had never received any treatment were most likely to be in their $30 \mathrm{~s}$ (55.6\%). Conclusion: This study suggests that a considerable number of HCV carriers have never received treatment for HCV infection. Currently in Japan, systems appear to be lacking which might prompt HCV positive individuals to visit hepatology specialists and obtain appropriate treatment.
\end{abstract}

Keywords: Care, carrier, hepatitis C, Japan, working.

\section{INTRODUCTION}

Progression of viral hepatitis to liver cirrhosis and even liver cancer can often be prevented by appropriate treatment, especially if the infection is identified at an early stage $[1,2]$. In Japan, the Basic Act on Hepatitis Measures was enacted in 2009 and has been supporting and promoting a project to provide opportunities for viral hepatitis screening [3]. Although it is important for persons with $\mathrm{HCV}$ infection to receive continuous treatment [4], such individuals may not be motivated to do so because they are often asymptomatic for a long period of time [5]. However, as a result of recent improvements in the treatment of HCV infection, the therapeutic scope has expanded to include carriers who were not previously targeted for treatment [6]. Effective treatments were generally lacking in the past for persons infected with HCV and some prejudice against these people may also exist [7].

At a practical level, HCV carriers also need to undergo follow-up treatment such as abdominal ultrasonography once every 4-6 months and hematological examination once every 2 months for managing hepatocellular carcinoma, even when the alanine aminotransferase level is $<80 \mathrm{IU} / 1$, in accordance with current guidelines [8]. Carriers of working age are an important target of early-phase treatment, and it is also necessary to detect hepatic cirrhosis and cancer at an early stage in this population [9]. Despite these facts however, it

*Address correspondence to this author at the Bureau of International Medical Cooperation, National Institute for Global Health and Medicine, 1-21-1 Toyama, Shinjuku-ku, Tokyo 162-8655, Japan; Tel: +81-3-6228-0327; Fax: +81-3-3205-7860; E-mail: kwada-sgy@umin.ac.jp remains unclear exactly what proportion of the Japanese working population has already undergone testing. The aim of this study was, therefore, to investigate ongoing care and follow-up behaviors of working age Japanese who are currently infected with $\mathrm{HCV}$.

\section{METHODS}

\section{Recruitment of Participants}

Nineteen thousand and four hundred Japanese people of working age (20-69 years) who had agreed to respond to various health-related issues were randomly extracted from the registry of an internet research company in September 2012. All participants who were interested in taking part in the survey had initially been offered a financial incentive to respond and had voluntarily registered with the survey company. From this group, persons who had been previously infected with HCV were identified as follows. Firstly, a letter was sent to HCV-infected persons asking if they had undergone treatment for various diseases such as type 1 and 2 diabetes, hyperuricemia, hypercholesterolemia, hepatitis B, hepatitis $\mathrm{C}$, or chronic renal failure to ensure that the survey was aimed at identifying HCV cases. After the survey company had identified 138 male and 156 female individuals with $\mathrm{HCV}$ infection, an additional letter was sent to them which included questions designed for the present study. Although the questionnaire was anonymous, respondents were required to consent to the results being published in academic journals. The web survey company ceased recruitment when the total number of participants reached the target number. Participants were recruited in clusters, target- 
ing 75 individuals of each sex for $\mathrm{HCV}$ infection, giving a total of 150 respondents in the first instance.

\section{Questionnaire}

The questionnaire utilized in this study was anonymous. Participants were asked their age and occupation (company employee, self-employed, or part-time), and were then requested to choose one of the following categories pertaining to how they had found out about being infected with HCV. The answer choices were as follows: (1) at a regular health check-up; (2) at the time of pregnancy health screening or pre-surgical screening in a hospital; (3) at a visit to a medical facility because of ill health; (4) at the time of blood donation; (5) at a visit to a medical facility prompted by anxiety regarding blood transfusion or the use of blood products in the past; and (6) other reasons. Participants were asked if they had received any specific treatment for HCV. Participants were also requested to select an answer from the following regarding the frequency of visits to medical facilities for HCV infection in the previous year: (1) at least once a week; (2) about once a month; (3) about once every 3 months; (4) about once every 6 months; (5) about once a year; or (6) no periodic visits. Participants who reported that they had received no prior medications for their infection were asked to give reasons by choosing at least one of the following: (1) there were no subjective symptoms; (2) my doctor did not recommend it; (3) bothersome; (4) too busy working; (5) financially difficult; (6) completely cured; or (7) anxious about work colleagues finding out about my infection status / did not want anyone at work to know.

\section{Statistical Analysis}

The proportion of respondents who were receiving and not receiving any form of treatment or follow-up from physicians for HCV infection was ascertained. We then identified the characteristics of persons who had not been treated for $\mathrm{HCV}$ infection by cross tabulation. For each calculation the $95 \%$ confidence interval was calculated, with IBM SPSS Statistics version 20 was used for all statistical analyses.

\section{Ethics}

This study was approved by the Kitasato University School of Medicine Ethics Committee prior to implementation. We obtained a written informed consent for participation in this study from each respondent.

\section{RESULTS}

Completed responses to the questionnaire were obtained from 156 individuals for who their characteristics are shown on Table 1. A total of 156 persons who had been diagnosed with HCV were extracted to obtain a male-to-female ratio of $1: 1$. Respondents in their $50 \mathrm{~s}$ accounted for the largest proportion of both genders; while for occupation, company employees were the most common in both genders. HCV infection was discovered during a regular health check-up in $29.5 \%$ and during a visit to a medical facility because of ill health in $28.2 \%$ of cases. Infection was discovered at the time of blood donation among $14.1 \%$ of HCV carriers. There was a history of no prior treatment for HCV infection reported by $35.9 \%$ of HCV carriers, with $30.1 \%$ of HCVinfected individuals reporting no periodic visits. Table 2 in- dicates the percentages for prior treatment, frequency of visits to medical facilities in the previous year, and reasons for not visiting medical facilities for HCV infection, stratified by gender. The proportion of individuals reporting no prior treatment was higher among women (44.9\%) than men $(26.9 \%)$. With regard to the frequency of visits to medical facilities, no regular visits were reported by $29.5 \%$ of men and $30.8 \%$ of women with HCV infection. The main reasons for not visiting were that the illness had been cured $(61.9 \%$ of men), and the lack of a doctor's recommendation to visit a medical facility (31.4\% of women).

Table 1. Participant characteristics.

\begin{tabular}{|c|c|c|}
\hline & $\mathbf{N}$ & $(\%)^{*}$ \\
\hline \multicolumn{3}{|l|}{ Gender } \\
\hline Male & 78 & $(50.0)$ \\
\hline Female & 78 & $(50.0)$ \\
\hline \multicolumn{3}{|l|}{ Age (yrs) } \\
\hline $20-29$ & 4 & $(2.6)$ \\
\hline $30-39$ & 18 & $(11.5)$ \\
\hline $40-49$ & 45 & $(28.8)$ \\
\hline $50-59$ & 59 & $(37.8)$ \\
\hline $60-69$ & 30 & $(19.2)$ \\
\hline \multicolumn{3}{|l|}{ Occupation } \\
\hline Company employee & 80 & $(51.3)$ \\
\hline Self-employed & 32 & $(20.5)$ \\
\hline Part-time & 44 & $(28.2)$ \\
\hline \multicolumn{3}{|l|}{ HCV Infection Status Discovery } \\
\hline At a regular health check-up & 46 & $(29.5)$ \\
\hline $\begin{array}{l}\text { At the time of pregnancy health screening or } \\
\text { pre-surgical screening }\end{array}$ & 34 & $(21.8)$ \\
\hline At a visit to a medical facility due to ill health & 44 & $(28.2)$ \\
\hline At the time of blood donation & 22 & $(14.1)$ \\
\hline $\begin{array}{l}\text { At a visit to a medical facility prompted by } \\
\text { anxiety regarding blood transfusion or the use } \\
\text { of blood products in the past }\end{array}$ & 9 & $(5.8)$ \\
\hline Other Reason & 5 & $(3.2)$ \\
\hline \multicolumn{3}{|l|}{ Prior Treatment for HCV Infection } \\
\hline Yes & 100 & $(64.1)$ \\
\hline No & 56 & $(35.9)$ \\
\hline \multicolumn{3}{|l|}{ Frequency of Visits to Medical Facilities } \\
\hline At least once a week & 8 & $(5.1)$ \\
\hline About once a month & 26 & $(16.7)$ \\
\hline About once every three months & 32 & $(20.5)$ \\
\hline About once every six months & 17 & $(10.9)$ \\
\hline About once a year & 26 & $(16.7)$ \\
\hline No periodic visits & 47 & $(30.1)$ \\
\hline
\end{tabular}


Table 2. Prior treatment for hepatitis $\mathrm{C}$ virus (HCV) infection.

\begin{tabular}{|c|c|c|c|c|}
\hline & \multicolumn{2}{|c|}{ Male } & \multicolumn{2}{|c|}{ Female } \\
\hline \multicolumn{5}{|c|}{ Prior Treatment for HCV Infection } \\
\hline Yes & 73.1 & $(63.2-82.9)$ & 55.1 & $(44.1-66.2)$ \\
\hline No & 26.9 & $(17.1-36.8)$ & 44.9 & $(33.8-55.9)$ \\
\hline At least once a week & 5.1 & $(0.2-10.0)$ & 5.1 & $(0.2-10.0)$ \\
\hline About once a month & 21.8 & $(12.6-31.0)$ & 11.5 & $(4.4-18.6)$ \\
\hline About once every three months & 20.5 & $(11.6-29.5)$ & 20.5 & $(11.6-29.5)$ \\
\hline About once every six months & 10.3 & $(3.5-17.0)$ & 11.5 & $(4.4-18.6)$ \\
\hline Reason for not Visiting Medical Facilities & $(\mathrm{n}=21)$ & & $(\mathrm{n}=35)$ & \\
\hline No subjective symptoms & 14.3 & $(0-29.3)$ & 28.6 & $(13.6-43.5)$ \\
\hline My doctor did not recommend it & 19.0 & $(2.3-35.8)$ & 31.4 & $(16.0-46.8)$ \\
\hline Bothersome & 0.0 & - & 14.3 & $(2.7-25.9)$ \\
\hline Too busy working & 9.5 & $(0-22.1)$ & 5.7 & $(0-13.4)$ \\
\hline Financially difficult & 19.0 & $(2.3-35.8)$ & 5.7 & $(0-13.4)$ \\
\hline Completely cured & 61.9 & $(41.1-82.7)$ & 8.6 & $(0-17.8)$ \\
\hline
\end{tabular}

$* 95 \%$ Confidence Intervals

Table 3 indicates the proportion of respondents with $\mathrm{HCV}$ infection who had not received any prior treatment. Those without prior treatment were most frequently in their 30 s $(55.6 \%)$, while part-time workers without prior treatment accounted for $40.9 \%$ of those with HCV infection. Based on when the infection had been detected, $44.4 \%$ of their detections occurred at a visit to a medical facility prompted by anxiety regarding blood transfusion or use of blood products in the past, with further $41.2 \%$ occurring at the time of health screening for pregnancy or pre-surgical screening in a hospital.

\section{DISCUSSION}

Overall, this study suggests that a considerable proportion of working-age Japanese people have not received treatment or follow-up for HCV infection, with HCV carriers most likely to seek treatment only when deterioration of their physical condition prompted a visit to medical facilities. Furthermore, detection of their infection did not necessarily lead to treatment when discovered at the time of blood donation, pregnancy or pre-surgical health screening in a hospital which did not have a direct link for specialists of hepatology. The gap between screening opportunities and post-diagnosis care of $\mathrm{HCV}$ infection needs to be addressed [10]. Infection with $\mathrm{HCV}$ was most frequently detected when the carrier visited a medical facility because of ill health, and the lack of prior treatment for viral hepatitis was less frequent among these carriers when compared to others. Although it is unclear whether the ill health suffered by participants in the current study was attributable to HCV infection; in research from the United States a similar proportion of $\mathrm{HCV}$-infected persons were identified due to liver related symptoms [11]. Where HCV status was discovered during blood donation, blood sampling during pregnancy or screening prior to surgery; the lack of treatment which was slightly more common among HCV carriers suggests a general failure in referring these individuals to appropriate specialists. As such, it is clearly necessary to emphasize post-test counseling for those with positive results and to establish more effective linkage to follow-up care and treatment by appropriate hepatology specialists [12].

In the current study, a lack of prior treatment was more frequent among female than male HCV carriers, which is similar to a previous study of $\mathrm{HCV}$-infected patients conducted in the United States [13]. In addition, it was suggested that population groups that were more likely not to receive treatment included those aged in their 30s; a situation which may reflect marital status (a known barrier to treat- 
ment) [13] and being self-employed, for whom treatment can interrupt their ability to make a living. In Japan, although economic aid is available for people who need treatment for $\mathrm{HCV}$ infection [3], further measures should still be considered to facilitate their visits to hepatologists. Additional work also needs to be done regarding potential prejudice for these infections in the workplace [14]. With regard to periodic visits to medical facilities for treatment of HCV infection, individuals who reported no visits accounted for the largest proportion, and this was explained by an absence of subjective symptoms and the absence of a doctor's recommendation to seek follow-up care. It is desirable for all primary care doctors in Japan, as elsewhere, to ensure that HCV carriers whom they see in their practice undergo appropriate follow-up by hepatology specialists [15].

Table 3. Characteristics of hepatitis $\mathrm{C}$ virus (HCV) carriers with no treatment history.

\begin{tabular}{|c|c|c|}
\hline & $\% *$ & $(95 \% \mathrm{CI})^{* *}$ \\
\hline \multicolumn{3}{|l|}{ Gender } \\
\hline Male & 26.9 & $(19.9-33.9)$ \\
\hline Female & 44.9 & $(37.0-52.7)$ \\
\hline \multicolumn{3}{|l|}{ Age } \\
\hline $20-29$ & 25 & $(0-55.0)$ \\
\hline $30-39$ & 55.6 & $(42.2-69.0)$ \\
\hline $40-49$ & 37.8 & $(27.5-48.1)$ \\
\hline $50-59$ & 32.2 & $(23.5-40.8)$ \\
\hline $60-69$ & 30 & $(17.8-42.2)$ \\
\hline \multicolumn{3}{|l|}{ Occupation } \\
\hline Company Employee & 33.8 & $(26.9-40.7)$ \\
\hline Self-employed & 34.4 & $(21.5-47.3)$ \\
\hline Part-time & 40.9 & $(30.0-51.7)$ \\
\hline \multicolumn{3}{|l|}{ HCV Infection Status Discovery } \\
\hline At a regular health check-up $(n=46)$ & 37 & $(23.0-51.0)$ \\
\hline $\begin{array}{l}\text { At the time of health screening for } \\
\text { pregnancy or pre-surgical screen- } \\
\text { ing }(n=34)\end{array}$ & 41.2 & $(24.7-57.7)$ \\
\hline $\begin{array}{l}\text { At visit to a medical facility be- } \\
\text { cause of ill health }(n=44)\end{array}$ & 38.6 & $(24.2-53.0)$ \\
\hline $\begin{array}{l}\text { At the time of blood donation } \\
(\mathrm{n}=22)\end{array}$ & 13.6 & $(0-27.9)$ \\
\hline $\begin{array}{l}\text { At visit to a medical facility } \\
\text { prompted by anxiety regarding } \\
\text { blood transfusion or use of blood } \\
\text { products in the past }(\mathrm{n}=9)\end{array}$ & 44.4 & $(11.9-76.9)$ \\
\hline Other Reason $(\mathrm{n}=5)$ & 46.2 & $(19.1-73.3)$ \\
\hline
\end{tabular}

$*_{n}=56$

$* * 95 \%$ Confidence Intervals
Although it was one of the first of its kind in Japan, the current study had certain limitations that must be taken into consideration when interpreting the results. Firstly, as it was a web-based survey, the participants we recruited had access to the internet and had volunteered to participate in such a survey - conditions which may in turn, impart a certain degree of selection bias. Secondly, given the fact that we investigated a sub-section of a sub-section of the community, our sample size was rather small. As a result, further investigations of a larger scale are now necessary to establish the national Japanese situation. Thirdly, our study utilized selfreported data on all responses, especially with regard to HCV status and could thus, not be verified by objective laboratory data. To address this issue in future research, HCVRNA status will need to be clinically established.

\section{CONCLUSION}

In conclusion, the current study suggests that a considerable proportion of Japanese HCV carriers have never received treatment for their infection. No official systems currently exist in Japan which will prompt HCV carriers to visit specialists in hepatology, even for those whose infections are confirmed by laboratory testing. This clearly needs to be addressed at a national level. Intervention is also necessary for members of the Japanese population who have already been diagnosed as HCV carriers but who are not receiving any treatment or regular clinical follow-up.

\section{CONFLICT OF INTEREST}

The authors confirm that this article content has no conflict of interest.

\section{ACKNOWLEDGEMENTS}

This study was funded by a Health Labour Sciences Research Grant from The Ministry of Health, Labour, and Welfare (H23-Hepatitis-General-005). The funders had no role in study design, data collection and analysis, the decision to publish, or preparation of the manuscript.

\section{REFERENCES}

[1] Liaw YF. Natural history of chronic hepatitis B virus infection and long-term outcome under treatment. Liver Int 2009; 29(s1): 100-7.

[2] Sroczynski G, Esteban E, Conrads-Frank A, et al. Long-term effectiveness and cost-effectiveness of screening for hepatitis $\mathrm{C}$ virus infection. Eur J Public Health 2009; 19(3): 245-53.

[3] Ministry of Justice. Basic Act on Hepatitis Measures 2009 Available from: http://www.japaneselawtranslation.go.jp/law/ detail/ $/ \mathrm{id}=1995 \& \mathrm{vm}=04 \& \mathrm{re}=01$ [Accessed on 15-Sept-2014].

[4] Perz JF, Armstrong GL, Farrington LA, Hutin YJ, Bell BP. The contributions of hepatitis $B$ virus and hepatitis $C$ virus infections to cirrhosis and primary liver cancer worldwide. J Hepatol 2006; 45(4): 529-38.

[5] Szpakowski JL, Tucker LY. Causes of death in patients with hepatitis B: a natural history cohort study in the United States. Hepatology 2013; 58(1): 21-30.

[6] Ghany MG, Strader DB, Thomas DL, Seeff LB. Diagnosis, management, and treatment of hepatitis $C$ : an update. Hepatology (Baltimore, Md) 2009; 49(4): 1335-74.

[7] Sasaki N, Wada K, Smith DR, Wang G, Ohta H, Shibuya A Hepatitis screening in Japanese individuals of working age and prejudice against infected persons in the workplace. J Occup Health 2014; 55(5): 392-7. 
[8] Clinical Practice Guidelines for Hepatocellular Carcinoma - The Japan Society of Hepatology 2009 update. Hepatol Res 2010; 40 (1): 2-144

[9] Kumada H, Okanoue T, Onji M, et al. Guidelines for the treatment of chronic hepatitis and cirrhosis due to hepatitis B virus infection for the fiscal year 2008 in Japan. Hepatol Res 2010; 40(1): 1-7.

[10] Shehab TM, Sonnad SS, Lok AS. Management of hepatitis C patients by primary care physicians in the USA: results of a national survey. J Viral Hepat 2001; 8(5): 377-83.

[11] Locations and reasons for initial testing for hepatitis C infection chronic hepatitis cohort study, United States, 2006-2010. MMWR Morb Mortal Wkly Rep 2013; 62(32): 645-8.

[12] Smith BD, Morgan RL, Beckett GA, et al. Recommendations for the identification of chronic hepatitis $\mathrm{C}$ virus infection among persons born during 1945-1965. MMWR Morb Mortal Wkly Rep 2012; 61(RR-4): 1-32.

[13] Morrill JA, Shrestha M, Grant RW. Barriers to the treatment of hepatitis C. Patient, provider, and system factors. J Gen Intern Med 2005; 20(8): 754-8.

[14] Eguchi H, Wada K, Smith DR. Sociodemographic factors and prejudice toward HIV and hepatitis $\mathrm{B} / \mathrm{C}$ status in a working-age population: results from a national, cross-sectional study in Japan. PloS One 2014; 9(5): e96645.

[15] Ferrante JM, Winston DG, Chen PH, de la Torre AN. Family physicians' knowledge and screening of chronic hepatitis and liver cancer. Fam Med 2008; 40(5): 345-51.

Received: June 15, 2014

Revised: August 22, 2014

Accepted: September 02, 2014

(C) Wada et al.; Licensee Bentham Open.

This is an open access article licensed under the terms of the Creative Commons Attribution Non-Commercial License (http://creativecommons.org/licenses/by-nc/3.0/) which permits unrestricted, non-commercial use, distribution and reproduction in any medium, provided the work is properly cited. 